\title{
Perbandingan Algoritma K-Means dan K-Medoids Untuk Pengelompokkan Data Obat dengan Silhouette Coefficient
}

\author{
Riva Arsyad Farissa ${ }^{1}$, Rini Mayasari ${ }^{2}$, Yuyun Umaidah $^{3}$ \\ ${ }^{1,2,3}$ Prodi Teknik Informatika Universitas Singaperbangsa Karawang \\ riva.arsyad17184@student.unsika.ac.id ${ }^{1}$, rini.mayasari@staff.unsika.ac.id $^{2}$, yuyun.umaidah@staff.unsika.ac.id ${ }^{3}$
}

\begin{abstract}
Article Info
Article history:

Received 2021-08-07

Revised 2021-09-20

Accepted 2021-09-25

Keyword:

K-Means,

K-Medoids,

Silhouette Coefficient.

ABSTRACT

Perencanaan kebutuhan obat yang tidak efektif dan efisien menyebabkan masalah tentang tidak meratanya distribusi obat-obatan di setiap puskesmas. Dengan penggunaan data mining kebutuhan obat-obatan dapat dikendalikan agar tidak terjadi penumpukan stok serta kehabisan stok obat. Teknik clustering ini sangat cocok digunakan dalam perencanaan kebutuhan obat-obatan agar diketahui stok obat yang stabil dan tidak stabil. Metode yang akan digunakan untuk clustering data obatobatan adalah algoritma $K$-Means dan $K$-Medoids. Tujuan dari penelitian ini adalah untuk mengelompokkan data obat-obatan di Puskesmas Karangsambung yang dapat digunakan sebagai referensi untuk perencanaan obat yang akan datang di puskesmas tersebut. Pengelompokkan data dibagi menjadi tiga yaitu lambat, sedang dan cepat. Hasil yang didapatkan yaitu kedua algoritma tersebut menunjukan bahwa algoritma K-Means mendapatkan hasil Silhouette Coefficient lebih tinggi yaitu sebesar 0,627 sedangkan $K$-Medoids sebesar 0,536 yang artinya hasil clustering $K$-Means lebih berkualitas dibandingkan $K$-Medoids. Dengan hasil dari pengelompokkan obat tersebut puskesmas dapat melakukan pemerataan stok obat agar tidak terdapat kelebihan dan kekurangan stok obat.
\end{abstract}

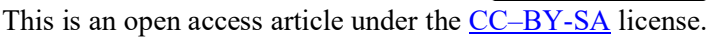

\section{Pendahuluan}

Puskesmas merupakan unit pelaksana fungsional yang berperan sebagai pusat pembangunan kesehatan, pusat partisipasi masyarakat bidang kesehatan dan pusat pelayanan kesehatan primer yang menyelenggarakan kegiatan secara komprehensif, terpadu, dan berkelanjutan di suatu wilayah tertentu. Dalam proses pengadaan, bagian obat melakukan pengecekan deposit puskesmas, kemudian melihat tingkat fungsionalnya dengan sisa stok, tingkat kebutuhan dan kasus yang sering ditemukan. Kemudian petugas obat meminta barang-barang yang harus di stok ulang, untuk diteruskan ke bagian gudang obat. Sehubungan dengan semakin meningkatnya aktivitas medis khususnya di bagian obatobatan, ditemukan beberapa permasalahan. Permasalahan yang ditemukan adalah tidak terkendalinya stok obat-obatan. Pengendalian obat adalah kegiatan untuk memastikan tercapainya tujuan yang diharapkan sesuai dengan strategi dan rencana yang telah dirumuskan, serta memastikan tidak terjadi kelebihan dan kekurangan obat [1]. Jika cara pengelolaan obat dilakukan secara efektif, efisien dan rasional maka ketersediaan dan keterjangkauan obat akan terjamin [2].

Oleh sebab itu, setiap puskesmas harus memiliki sistem pengolahan data yang baik agar data-data yang dihasilkan dari penggunaan obat tersebut dapat berguna untuk dibuat menjadi sebuah laporan bulanan atau tahunan. Data ini tidak hanya digunakan sebagai arsip, tetapi juga dapat digunakan dan diolah menjadi informasi yang berguna untuk meningkatkan pelayanan kesehatan. Dengan dilakukannya pengelompokkan obat maka dapat dilakukan pemerataan stok obat-obatan di setiap puskesmas.

Penerapan data mining di bidang kesehatan banyak dikemukakan peneliti, karena memiliki kemampuan mengekstrak data dalam jumlah besar untuk memperoleh informasi yang berguna [3]. Teknik data mining dapat digunakan secara luas di rumah sakit, klinik dan apotek oleh penyedia layanan kesehatan untuk memberikan layanan kesehatan yang lebih baik dan lebih terjangkau kepada pasien [4]. Penggunaan data mining ini dapat mengendalikan stok obat agar tidak terjadi penumpukan stok serta kehabisan stok

http://jurnal.polibatam.ac.id/index.php/JAIC 
obat. Clustering adalah teknik pengelompokan record dalam database berdasarkan kondisi tertentu. Konsep dasar clustering adalah mengelompokkan beberapa objek ke dalam cluster, dimana cluster yang baik adalah cluster yang memiliki tingkat kemiripan yang tinggi antara objek-objek dalam cluster tersebut dan tingkat ketidaksamaan yang tinggi dengan objek cluster lainnya. Alasan penggunaan algoritma $K$-means dan $K$-medoids clustering ini dikarenakan algoritma ini memiliki akurasi yang cukup tinggi dan efisien dalam memproses obyek dalam jumlah besar. Selain itu kelebihan metode K-Means dan K-Medoids mempunyai sifat yang fleksibel karena user dapat menentukan jumlah cluster yang akan dibuat [5].

Penelitian tentang perbandingan clustering $k$ - means dan hierarchical clustering single linkage pada persediaan obat. Penelitian ini menganalisis tentang penggunaan obat sehingga dapat dilakukan perencanaan stok obat. Hasil dari penelitian ini didapatkan nilai evaluasi algoritma $K$-means sebesar 0.8014 dan HCC Single sebesar 0.8629 [6]. Penelitian lain tentang analisis K-medoids Clustering untuk mengelompokkan data imunisasi campak balita di Indonesia dengan 2 kali iterasi dengan hasil 3 cluster yakni cluster rendah sebanyak 2 provinsi cluster sedang sebanyak 30 provinsi dan cluster tinggi sebanyak 2 provinsi [7]. Penelitian lainnya yang berjudul Comparative Analysis of K-means and $K$-medoids Algorithm on IRIS Data mengenai perbandingan algoritma $K$-means dan $K$-medoids menggunakan dataset tanaman iris hasil yang diperoleh $K$-medoids lebih baik daripada $K$-means untuk akurasi pengelompokan terhadap kelas-kelas yang sebenarnya sehingga nilai $K$-means adalah $88,7 \%$ dan untuk $K$-medoids yaitu $92 \%$ [8].

Berdasarkan latar belakang di atas, maka penelitian ini akan melakukan pengelompokkan data obat berdasarkan jenis obat, pemasukan dan penggunaan obat. Dengan melakukan analisa data obat di Puskesmas Karangsambung, diharapkan Puskesmas Karangsambung dapat menentukan keputusan yang tepat dalam pengendalian stok obat. Berdasarkan dari akurasi dan nilai akhir yang baik dari metode yang digunakan pada penelitian sebelumnya, maka metode yang digunakan adalah metode cluster analysis menggunakan algoritma $K$ means dan $K$-medoids. Pemprosesan pada penelitian ini akan dilakukan dengan bantuan Bahasa pemprograman Python.

\section{METODOLOGI PENELITIAN}

Metode data mining yang digunakan dalam penelitian ini adalah Cross-Industry Standard Process for Data mining (CRISP-DM). CRISP-DM adalah framework data mining yang secara garis besar terdiri dari 6 alur proses yang dimulai dari pemahaman bisnis hingga penerapan pengetahuan [9]. Tahapan yang akan dilakukan dengan CRISP-DM seperti gambar 1 berikut:

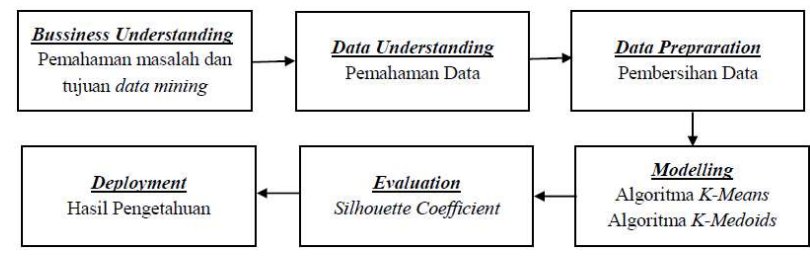

Gambar 1. Rancangan Penelitian CRISP-DM

Berikut ini adalah penjelasan dari tahapan metode CRISP-DM, yaitu:

A. Bussiness Understanding

Business Understanding adalah tahapan pendefinisian masalah dan objektif dari data mining yang akan dilakukan. Pada fase ini dibutuhkan pemahaman terkait masalah dan tujuan yang akan diselesaikan oleh data mining.

B. Data Understanding

Data Understanding adalah tahap pengumpulan koleksi data awal, dan melakukan proses pengenalan terhadap data tersebut dengan tujuan untuk lebih mengenal nature dari data yang akan dipakai

\section{Data Preparation}

Aktivitas-aktivitas yang dilakukan pada fase ini meliputi pemilihan data yang akan digunakan untuk proses modelling, proses data preprocessing seperti mengatasi outlier, noisy data, inconsistent dan missing value yang ada dan data transformation, melakukan normalisasi data. Hasil dari tahap ini akan digunakan untuk proses modelling.

\section{Modelling}

Tahap ini mengerjakan aktivitas terkait algoritma data mining yang akan digunakan. Berikut ini metode yang akan digunakan dalam tahap modelling yaitu:

1) K-Means

K-means adalah sebuah algorima data mining unsupervised yang menggunakan centroid sebagai titik pusat dalam setiap cluster. K-means ialah algoritma yang tidak rumit, ukuran kesamaan berperan penting dalam proses clustering menggunakan K-Means [10]. Algoritma clustering $K$-means banyak digunakan karena algoritmanya yang sederhana dan konvergensi yang cepat. Namun, nilai K clustering perlu diberikan terlebih dahulu dan pilihan nilai $\mathrm{K}$ secara langsung mempengaruhi hasil konvergensi [11].Algoritma $K$-means merupakan algoritma yang diwakili oleh cluster yaitu centroid atau nilai rata-rata sebagai titik pusat cluster.

\section{2) K-Medoids}

Algoritma PAM (Partitioning Around Medoid) merupakan algoritma yang diwakili oleh cluster yaitu medoid. Algoritma ini lebih populer dengan sebutan Algoritma K-Medoids. Algoritma K-Medoids lebih baik daripada K-Means, karena pada $K$-Medoids kita menemukan k sebagai representasi objek untuk meminimalkan jumlah pertidaksamaan objek data, sedangkan pada $\mathrm{K}$-Means kita menggunakan jumlah jarak Euclidean pada objek data [12]. Jika dibandingkan dengan algoritma $K$-Means perbedaan terletak pada titik pusat cluster, K-Means menggunakan nilai rata-rata (mean) sebagai pusat cluster sedangkan $K$-Medoids menggunakan sebuah 
objek sebagai pusat cluster dan objek tersebut harus mewakili masing-masing dari cluster.

\section{E. Evaluation}

Pada tahap ini evaluasi yang digunakan yaitu Silhouette Coefficent yang berfungsi untuk menguji kualitas dari kluster lalu ditentukan keputusan apakah hasil data mining akan digunakan atau tidak.

Silhouete Coefficient terletak pada rentang antara nilai -1 sampai 1. Rentang nilai tersebut digunakan untuk menunjukkan kedekatan kemiripan data yang dikelompokkan didalam suatu cluster. Jika nilai rata-rata Silhouette Coefficient mendekati nilai 1, maka cluster semakin baik. Sebaliknya jika nilai rata-rata Silhouette Coefficient mendekati -1, maka cluster tersebut tidak baik. Berikut kriteria pengukuran nilai Silhouette Coefficient [13] pada tabel I.

TABEL I

KRITERIA SILHOUETTE COEFFICIENT

\begin{tabular}{|c|c|}
\hline Silhouette Coefficient & Kriteria Penilaian \\
\hline $0.7<\mathrm{SC} \leq 1.0$ & Stronge Structure \\
\hline $0.5<\mathrm{SC} \leq 0.7$ & Medium Structure \\
\hline $0.25<\mathrm{SC} \leq 0.5$ & Weak Structure \\
\hline $\mathrm{SC} \leq 0.25$ & No Structure \\
\hline
\end{tabular}

F. Deployment

Deployment adalah tahapan penggunaan hasil dari proses data mining.

\section{HASIL DAN PEMBAHASAN}

Hasil penelitian yang dilakukan berupa hasil clustering melalui proses $C R I S P-D M$ dengan menggunakan algoritma $K$-Means dan K-Medoids yang didukung oleh tools GoogleColab dengan bahasa pemprograman Python.

A. Bussiness Understanding

Pada tahapan ini diperlukan pemahaman tentang pentingnya pemanfaatan data distribusi obat, agar dapat digunakan untuk mengetahui pengelompokkan obat berdasarkan pengeluaran dan pemasukan obat yang akan diterapkan pada setiap puskesmas. Tujuan dalam penerapan data mining ini adalah agar setiap puskesmas mengetahui pengelompokkan obat mana saja yang termasuk obat lambat habis, sedang dan cepat habis. Dengan mengetahui pengelompokkan tersebut distribusi obat pada setiap puskesmas dapat terkendali.

\section{B. Data Understanding}

Data yang digunakan merupakan data Laporan Pemakaian dan Lembar Permintaan Obat (LPLPO) yang bersumber dari Puskesmas Karangsambung. Laporan Pemakaian dan Lembar Permintaan Obat (LPLPO) merupakan suatu pngelolahan terhadap obat yang pemakaian, distribusi, tingkatan stok, kebutuhan obat dibatasi dengan tujuan agar pemakaian yang ada dapat terkendali dengan baik

Data yang akan digunakan sebanyak 374 data dari bulan januari 2019 sampai dengan desember 2020. Data yang digunakan menggunakan format .xlsx (Excel). Atribut yang terdapat dalam data tersebut terdiri dari 8 atribut yaitu nama obat, stok awal, penerimaan, persediaan, pemakaian, stok akhir, stok optimal dan permintaan. Terlihat pada gambar 2 .

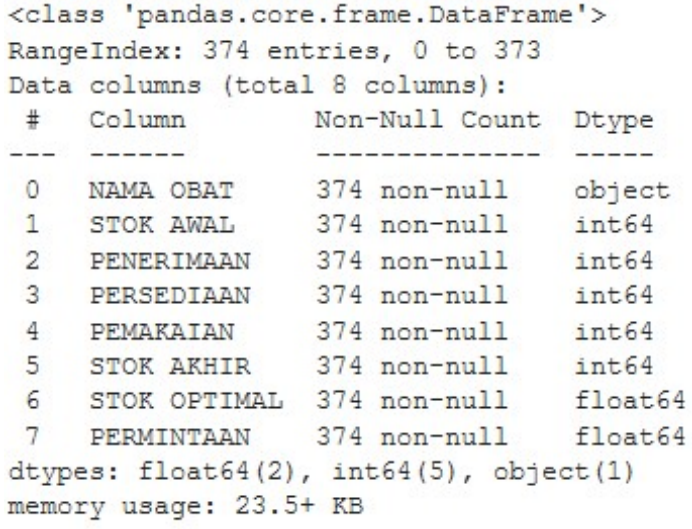

Gambar 2. Deskripsi Data

\section{Data Preparation}

Pada tahap ini hal pertama yang dilakukan adalah memilih atribut yang akan digunakan untuk proses modelling. Hal ini dilakukan karena atribut yang tidak berhubungan akan berpengaruh terhadap hasil dari modelling. Tahap ini dilakukan dengan cara menghapus atribut stok optimal dan permintaan, dikarenakan terdapat nilai yang tidak konsisten di dalam atribut tersebut. Berikut dari hasilnya dapat dilihat pada gambar 3 .

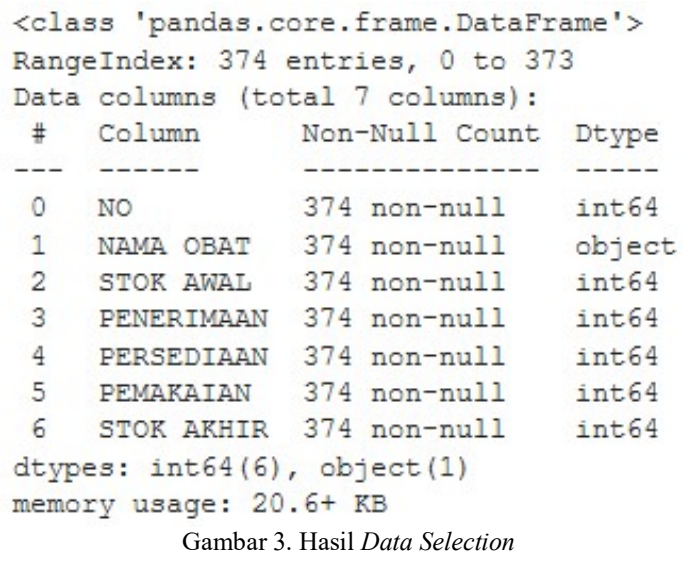

Setelah memilih atribut yang akan digunakan untuk proses modelling tahap selanjutnya yaitu mengatasi missing value seperti menghapus kolom yang hilang dan menghapus data yang tidak relevan seperti data yang pada semua atributnya bernilai " 0 ". Hal ini dilakukan agar proses modelling mendapatkan hasil yang baik. Setelah proses ini dilakukan jumlah kolom berkurang dari 373 menjadi 198 kolom. Adapun hasil dari prosesnya dapat dilihat pada tabel II. 
TABEL II

Hasil Mengatasi Missing Value

\begin{tabular}{|c|c|c|c|c|c|c|}
\hline No & Nama Obat & $\begin{array}{l}\text { Stok } \\
\text { Awal }\end{array}$ & Penerimaan & Persediaan & Pemakaian & $\begin{array}{l}\text { Stok } \\
\text { Akhir }\end{array}$ \\
\hline 0 & $\begin{array}{l}\text { Albendazol } \\
\text { Tablet } 400 \\
\text { Mg. }\end{array}$ & 14500 & 6300 & 20800 & 12700 & 8100 \\
\hline 1 & $\begin{array}{l}\text { Albendazol } \\
\text { Suspens/5mli } \\
200 \mathrm{Mg}\end{array}$ & 0 & 568 & 568 & 0 & 568 \\
\hline 2 & $\begin{array}{l}\text { Alopurinol } \\
\text { Tablet } 100 \\
\text { Mg. }\end{array}$ & 11400 & 3400 & 14800 & 3000 & 11800 \\
\hline$\ldots$ & $\ldots$ & .. & $\ldots$ & .. & $\ldots$ & .. \\
\hline 195 & $\begin{array}{l}\text { Lidokain Jelly } \\
2 \% \text { Syringe'10 }\end{array}$ & 120 & 30 & 150 & 30 & 120 \\
\hline 196 & $\begin{array}{l}\text { Bisakodil Tab } \\
5 \mathrm{Mg}\end{array}$ & 2440 & 300 & 2740 & 90 & 2650 \\
\hline 197 & $\begin{array}{l}\text { Omeprazole } \\
\text { Sodium } 40 \mathrm{Mg} \\
\text { Iv Inj }\end{array}$ & 860 & 100 & 960 & 96 & 864 \\
\hline
\end{tabular}

Tahap selanjutnya yaitu mengatasi outlier dengan cara menghapus outlier dengan perbandingan sebanyak $75 \%$ data yang akan digunakan dan $25 \%$ outlier dihapus dari data tersebut. Berikut merupakan cara mengatasi outlier dengan python.

for $x$ in ['STOK AKHIR']:

$q 75, q 25=n p \cdot \operatorname{percentile}(X \cdot \operatorname{loc}[:, x],[75,25])$

intr_qr $=q 75-q 25$

$\max =q 75+(1.5 *$ intr_qr $)$

$\min =q 25-(1.5 *$ intr_qr $)$

$x \cdot \operatorname{loc}[x[x]<\min , x]=n p \cdot$ nan

$\mathrm{X} \cdot \operatorname{loc}[\mathrm{X}[\mathrm{X}]>\max , \mathrm{X}]=\mathrm{np} \cdot \mathrm{nan}$

$X=X \cdot d r o p n a($ axis $=0)$

$X$.isnull().sum()

Hasilnya dapat terlihat pada gambar berikut ini.

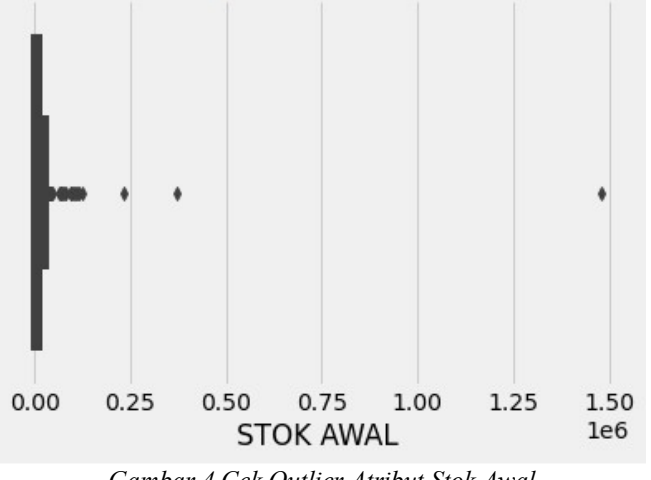

Gambar 4 Cek Outlier Atribut Stok Awal

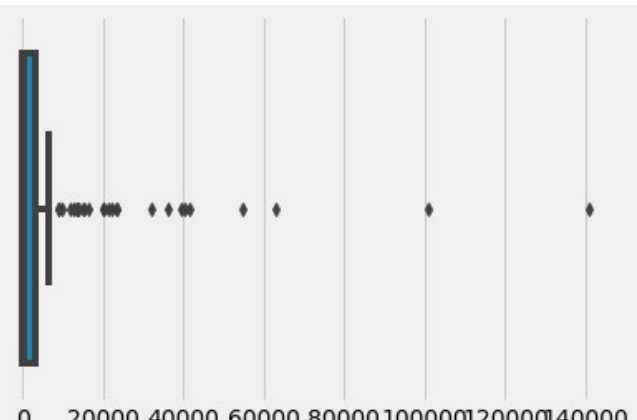

0 20000400006000080000100000120000140000 PENERIMAAN

Gambar 5 Cek Outlier Atribut Penerimaan

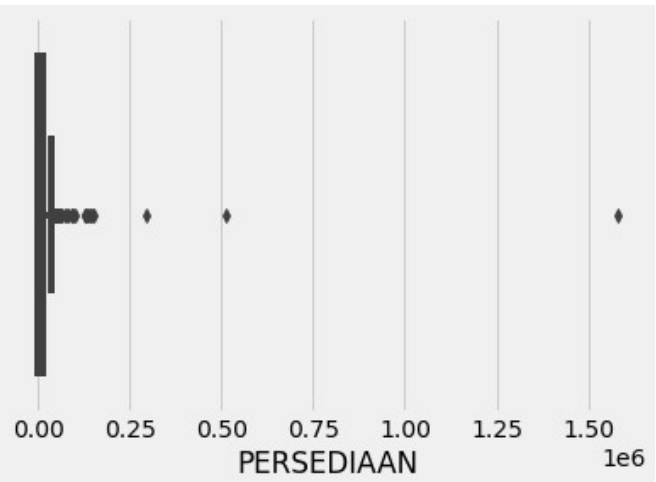

Gambar 6 Cek Outlier Atribut Persediaan

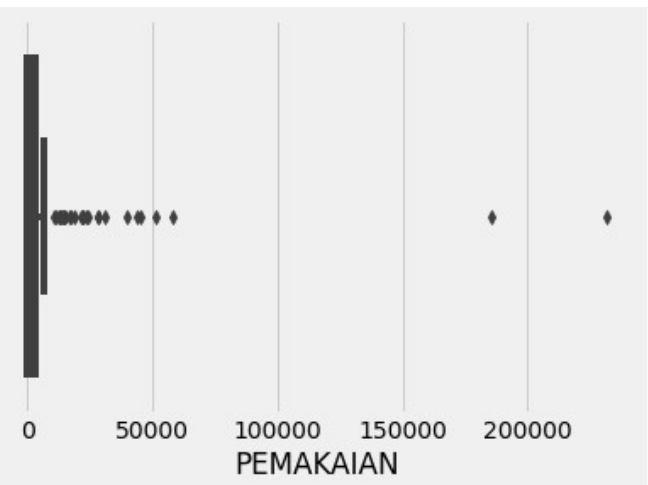

Gambar 7 Cek Outlier Atribut Pemakaian

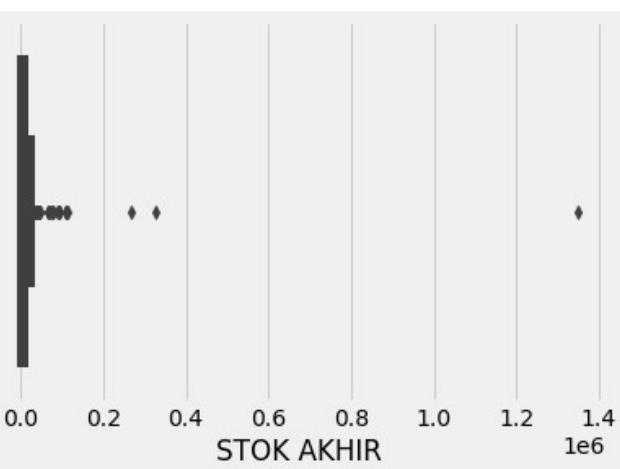

Gambar 8 Cek Outlier Atribut Stok Akhir 
Penghapusan outlier diperlukan karena outlier dapat menimbulkan hasil bias. Selain itu, hal ini berfungsi untuk mengatasi algoritma K-Means yang sensitif terhadap outlier. Hasil setelah penghapusan outlier jumlah data berkurang menjadi 163 kolom, terlihat pada tabel III.

TABEL III

Hasil Dataset Setelah Mengatasi OUTLIER

\begin{tabular}{|c|c|c|c|c|c|}
\hline No & $\begin{array}{c}\text { Stok } \\
\text { Awal }\end{array}$ & Penerimaan & Persediaan & Pemakaian & $\begin{array}{c}\text { Stok } \\
\text { Akhir }\end{array}$ \\
\hline 0 & 0 & 568 & 568 & 0 & 568 \\
\hline 1 & 11400 & 3400 & 14800 & 3000 & 11800 \\
\hline 2 & 8827 & 1000 & 9827 & 42 & 9785 \\
\hline$\ldots$ & $\ldots$ & $\ldots$ & $\ldots$ & $\ldots$ & $\ldots$ \\
\hline 160 & 120 & 30 & 150 & 30 & 120 \\
\hline 161 & 2440 & 300 & 2740 & 90 & 2650 \\
\hline 162 & 860 & 100 & 960 & 96 & 864 \\
\hline
\end{tabular}

Tahap selanjutnya yaitu transformasi data dengan cara melakukan normalisasi pada data. Proses normalisasi yang akan digunakan yaitu menggunakan cara Min-Max. Min-Max adalah metode normalisasi dengan melakukan transformasi linier terhadap data asli. Adapun hasil dari normalisasi data dapat dilihat pada tabel IV.

TABEL IV

HASIL NORMALISASI MIN-MAX

\begin{tabular}{|c|c|c|c|c|c|}
\hline No & Stok Awal & Penerimaan & Persediaan & Pemakaian & $\begin{array}{c}\text { Stok } \\
\text { Akhir }\end{array}$ \\
\hline 0 & 0 & 0.08875 & 0.017197 & 0 & 0.020505 \\
\hline 1 & 0.408602 & 0.53125 & 0.451153 & 0.441696 & 0.425993 \\
\hline 2 & 0.31638 & 0.15625 & 0.299518 & 0.006184 & 0.353249 \\
\hline$\ldots$ & $\ldots$ & $\ldots$ & $\ldots$ & $\ldots$ & $\ldots$ \\
\hline 160 & 0.004301 & 0.004687 & 0.004452 & 0.004417 & 0.004332 \\
\hline 161 & 0.087455 & 0.046875 & 0.083425 & 0.013251 & 0.095668 \\
\hline 162 & 0.030824 & 0.015625 & 0.02915 & 0.014134 & 0.031191 \\
\hline
\end{tabular}

\section{Modelling}

1) K-Means

Untuk dapat melakukan pengelompokan data dengan $K$ Means perlu menentukan jumlah cluster yang diperlukan. Data obat tersebut akan dikelompokkan mejadi tiga cluster yaitu Pemakaian Obat Lambat, Sedang dan Cepat atau k=3. Pengelompokkan tiga cluster dilakukan agar diketahui obat mana saja yang stabil atau sedang dan tidak stabil. Jarak yang digunakan untuk menghitung jarak terpendek yaitu menggunakan Euclidean distance. Hasilnya terlihat sebagai berikut.
Selanjutnya output dari program akan menampilkan centroid terakhir dan jumlah iterasi yang sudah di proses. Hasilnya seperti berikut ini.

Centroid Iterasi Terakhir :
$\left[\begin{array}{lllll}0.340654 & 0.2169895 & 0.3320222 & 0.2197143 & 0.3392551\end{array}\right]$
$\left[\begin{array}{lllll}0.044107 & 0.0476691 & 0.0467031 & 0.0375174 & 0.0462389\end{array}\right]$
$\left[\begin{array}{lllll}0.560367 & 0.7024739 & 0.6136749 & 0.7612877 & 0.5400511\end{array}\right]$

Jumlah Iterasi : 6

Hasil pengelompokan iterasi terakhir tersebut yaitu 30 obat pada cluster 0,121 obat pada cluster 1 dan 12 obat pada cluster 2. Gambar 10 bawah ini merupakan hasil visualisasi cluster dengan menggunakan algoritma K-Means.

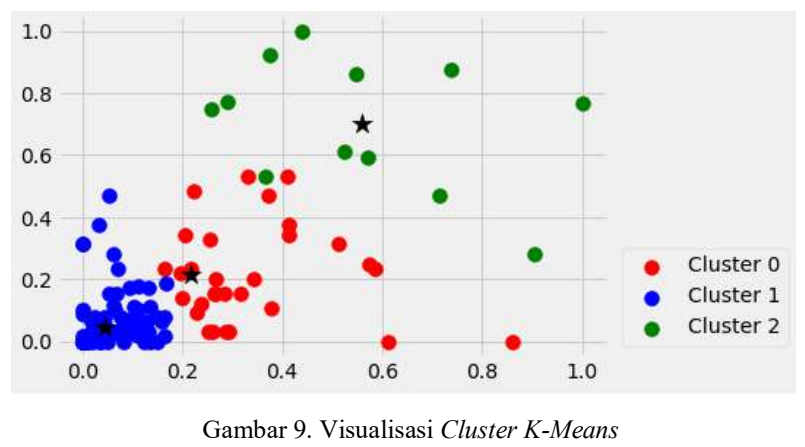

Selanjutnya melakukan analisis terhadap 3 cluster tersebut untuk penentuan label obat cepat habis, sedang dan lambat habis yang dilakukan berdasarkan karakteristik jumlah data stok obat dalam setiap cluster. Gambar 11 dan tabel V di bawah ini merupakan perbandingan karakteristik setiap cluster berdasarkan rata-rata dari keseluruhan atribut yang di tampilkan dalam bentuk persentase.

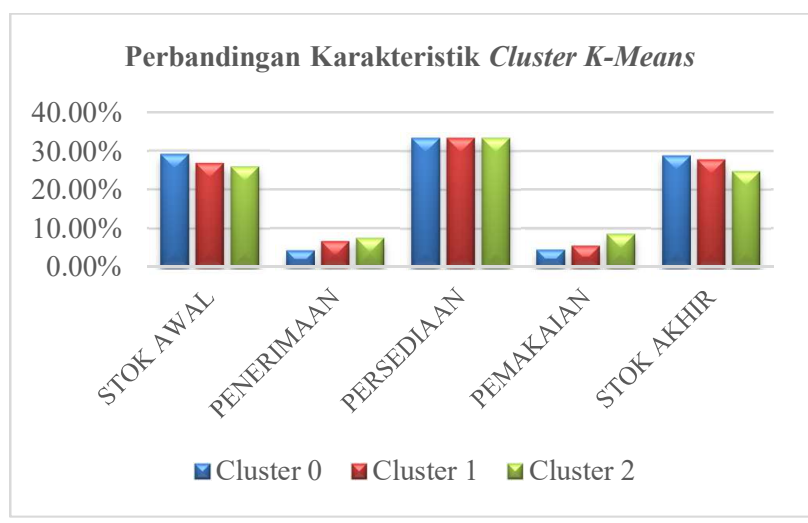

Gambar 10 Visualisasi Karakteristik Cluster K-Means

KMeans (algorithm=' auto', copy_x=True, init=' random', max_iter $=300, n_{-}$clusters $=3$, n_init $=10$, n_jobs=None, precompute_distances $=$ ' auto' , random_state $=42$, tol $=0.0001$, verbose $=0$ )

Perbandingan Algoritma K-Means dan K-Medoids Untuk Pengelompokkan Data Obat dengan Silhouette Coefficient (Riva Arsyad Farissa, Rini Mayasari dan Yuyun Umaidah) 
TABEL V

Perbandingan KaraKteristik Cluster K-Means

\begin{tabular}{|c|c|c|c|c|c|}
\hline & $\begin{array}{c}\text { Stok } \\
\text { Awal }\end{array}$ & $\begin{array}{c}\text { Penerima } \\
\text { an }\end{array}$ & $\begin{array}{c}\text { Persedia } \\
\text { an }\end{array}$ & $\begin{array}{c}\text { Pemakai } \\
\text { an }\end{array}$ & $\begin{array}{c}\text { Stok } \\
\text { Akhir }\end{array}$ \\
\hline $\begin{array}{c}\text { Cluster } \\
0\end{array}$ & $29.09 \%$ & $4.25 \%$ & $33.34 \%$ & $4.57 \%$ & $28.76 \%$ \\
\hline $\begin{array}{c}\text { Cluster } \\
1\end{array}$ & $26.71 \%$ & $6.62 \%$ & $33.33 \%$ & $5.53 \%$ & $27.80 \%$ \\
\hline $\begin{array}{c}\text { Cluster } \\
2\end{array}$ & $25.89 \%$ & $7.44 \%$ & $33.33 \%$ & $8.56 \%$ & $24.77 \%$ \\
\hline
\end{tabular}

Dari perbandingan karakteristik tersebut, hal yang paling disoroti adalah perbedaan signifikan antara persentase ratarata pemakaian dan stok akhir. Dalam penelitian ini pelabelan akan diambil dari selisih antara rata-rata pemakaian dengan stok akhir yang artinya semakin besar selisih maka pemakaian obat akan semakin lambat habis begitu pula sebaliknya semakin kecil selisih maka pemakaian obat akan semakin cepat habis. Berikut ini adalah hasil dari analisis pelabelan clustering.

a. Data obat cluster 0 dapat dikategorikan ke dalam cluster pemakaian obat lambat lambat. Hal ini dibuktikan dengan selisih antara rata-rata pemakaian dengan stok akhir yaitu $24.19 \%$.

b. Data obat cluster 1 dapat dikategorikan pemakaian obat sedang. Hal ini dibuktikan dengan selisih antara rata-rata pemakaian dengan stok akhir yaitu $22.27 \%$.

c. Data obat cluster 2 dapat dikategorikan pemakaian obat cepat. Hal ini dibuktikan dengan selisih antara rata-rata pemakaian dengan stok akhir yaitu $16.21 \%$.

\section{2) K-Medoids}

Untuk dapat melakukan pengelompokan data dengan $K$ Means perlu menentukan jumlah cluster yang diperlukan. Data obat tersebut akan dikelompokkan mejadi tiga cluster yaitu Pemakaian Obat Lambat, Sedang dan Cepat atau k=3. Pengelompokkan tiga cluster dilakukan agar diketahui obat mana saja yang stabil atau sedang dan tidak stabil. Jarak yang digunakan untuk menghitung jarak terpendek yaitu menggunakan Euclidean distance. Hasilnya seperti berikut.

Kmedoids ( init=' random', n_cluster $=3$, random_state $=42$

Selanjutnya output dari program akan menampilkan centroid terakhir dan jumlah iterasi yang sudah di proses. Hasilnya seperti berikut.

Medoid Iterasi Terakhir :

$\left.\begin{array}{lllll}{[0.1996415} & 0.140625 & 0.1971581 & 0.1236749 & 0.2032491] \\ {[0.5232974} & 0.609375 & 0.5639712 & 0.6625441 & 0.5054151] \\ {[0.0164874} & 0.014062 & 0.0166483 & 0.0103062 & 0.0173285]\end{array}\right]$

Hasil pengelompokan iterasi terakhir tersebut yaitu 43 obat pada cluster 0,20 obat pada cluster 1 dan 100 obat pada cluster 2. Gambar 14 merupakan hasil visualisasi cluster dengan menggunakan algoritma K-Medoids.

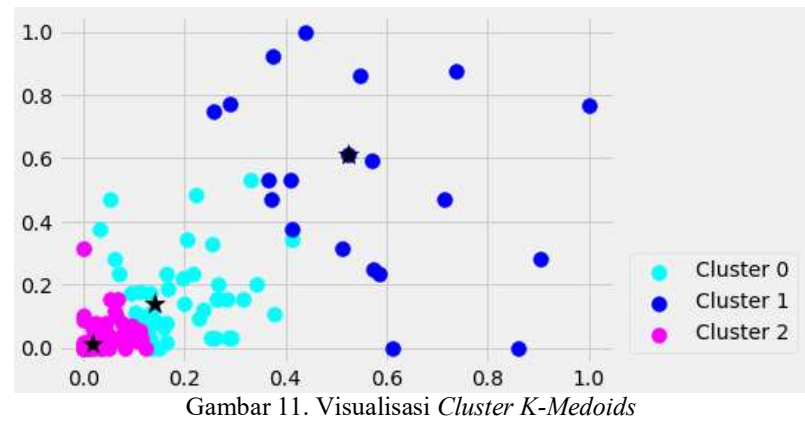

Selanjutnya melakukan analisis terhadap 3 cluster tersebut untuk penentuan label obat cepat habis, sedang dan lambat habis yang dilakukan berdasarkan karakteristik jumlah data stok obat dalam setiap cluster. Gambar 15 dan tabel VI di bawah ini merupakan perbandingan karakteristik setiap cluster berdasarkan rata-rata dari keseluruhan atribut yang di tampilkan dalam bentuk persentase.

\section{Perbandingan Karakteristik Cluster K-Medoids}

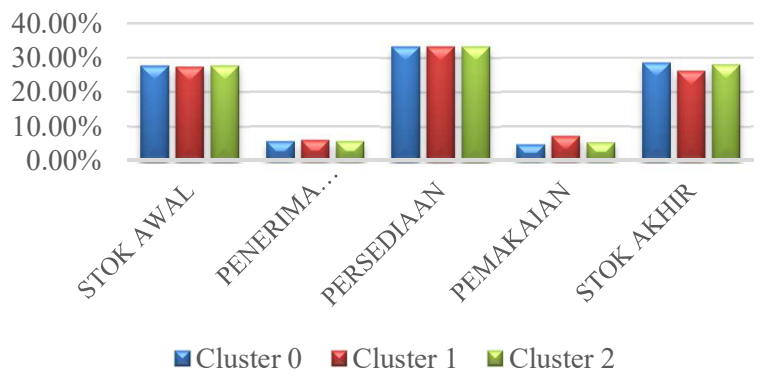

Gambar 12 Visualisasi Cluster K-Medoids

TABEL VI

Perbandingan KaraKteristik Cluster K-Medoids

\begin{tabular}{|c|c|c|c|c|c|}
\hline & $\begin{array}{c}\text { Stok } \\
\text { Awal }\end{array}$ & $\begin{array}{c}\text { Penerima } \\
\text { an }\end{array}$ & $\begin{array}{c}\text { Persedia } \\
\text { an }\end{array}$ & $\begin{array}{c}\text { Pemakai } \\
\text { an }\end{array}$ & $\begin{array}{c}\text { Stok } \\
\text { Akhir }\end{array}$ \\
\hline $\begin{array}{c}\text { Cluster } \\
0\end{array}$ & $27.64 \%$ & $5.70 \%$ & $33.34 \%$ & $4.82 \%$ & $28.51 \%$ \\
\hline $\begin{array}{c}\text { Cluster } \\
1\end{array}$ & $27.33 \%$ & $6.01 \%$ & $33.33 \%$ & $7.22 \%$ & $26.12 \%$ \\
\hline $\begin{array}{c}\text { Cluster } \\
2\end{array}$ & $27.60 \%$ & $5.73 \%$ & $33.33 \%$ & $5.35 \%$ & $27.98 \%$ \\
\hline
\end{tabular}

Dari perbandingan karakteristik tersebut, hal yang paling disoroti adalah perbedaan signifikan antara persentase ratarata pemakaian dan stok akhir. Dalam penelitian ini pelabelan akan diambil dari selisih antara rata-rata pemakaian dengan stok akhir yang artinya semakin besar selisih maka pemakaian obat akan semakin lambat habis begitu pula sebaliknya semakin kecil selisih maka pemakaian obat akan semakin cepat habis. Berikut ini adalah hasil dari analisis pelabelan clustering.

a. Data obat cluster 0 dapat dikategorikan ke dalam cluster pemakaian obat lambat lambat. Hal ini dibuktikan 
dengan selisih antara rata-rata pemakaian dengan stok akhir yaitu $23.69 \%$.

b. Data obat cluster 1 dapat dikategorikan pemakaian obat cepat. Hal ini dibuktikan dengan selisih antara rata-rata pemakaian dengan stok akhir yaitu $18.90 \%$.

c. Data obat cluster 2 dapat dikategorikan pemakaian obat sedang. Hal ini dibuktikan dengan selisih antara rata-rata pemakaian dengan stok akhir yaitu $22.63 \%$.

\section{E. Evaluation}

Evaluation berguna untuk mengukur kualitas hasil clustering. Teknik yang digunakan yaitu Sillhouette Coefficient. Proses evaluasi Silhoutte dilakukan sesuai jumlah $\mathrm{K}$ dan setelah hasil perhitungan dari proses $K$-Means dan $K$ Medoids selesai. Berikut ini merupakan hasil dari perhitungan kualitas cluster dengan menggunakan nilai $\mathrm{k}=3$ dapat dilihat pada gambar 16 .

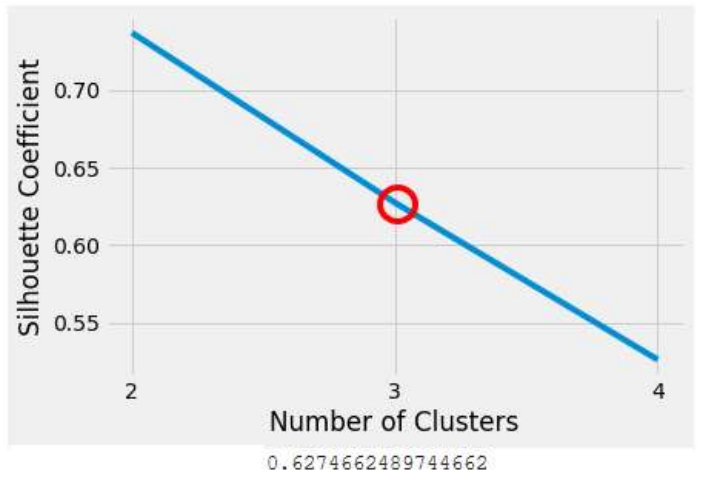

Gambar 13. Visualisasi Silhouette Coefficient K-Means

Berdasarkan gambar diatas dapat dilihat bahwa hasil akurasi menggunakan metode $K$-Means dengan nilai $\mathrm{k}=3$ didapatkan Silhouette Index sebesar 0,627 termasuk ke dalam kriteria Medium Structure. Untuk hasil algoritma K-Medoids dapat dilihat pada gambar 17 .

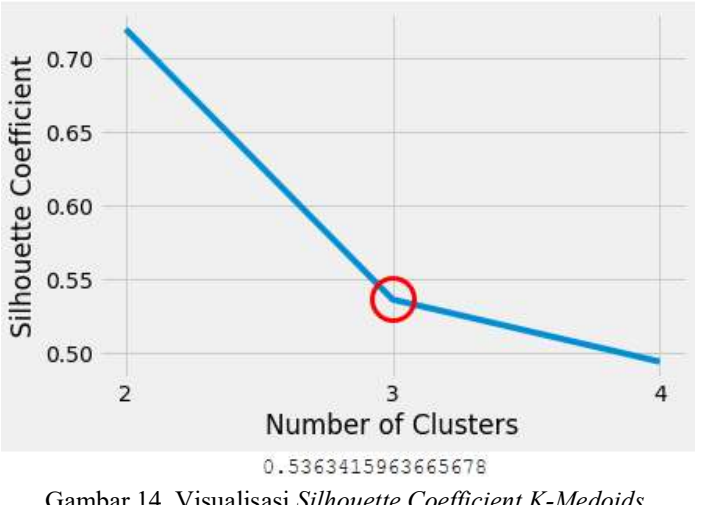

Berdasarkan gambar diatas hasil evaluasi dengan menggunakan metode $K$-Medoids didapatkan Silhoette Index sebesar 0,536 termasuk dalam kriteria Medium Structure.

F. Deployment
Pada tahap ini dilakukan proses pembuatan laporan hasil penelitian sehingga lebih mudah dipahami oleh orang awam dan sebagai bahan kajian untuk puskesmas dalam proses pengendalian obat. Gambar 18 merupakan persentase hasil dari cluster K-Means.

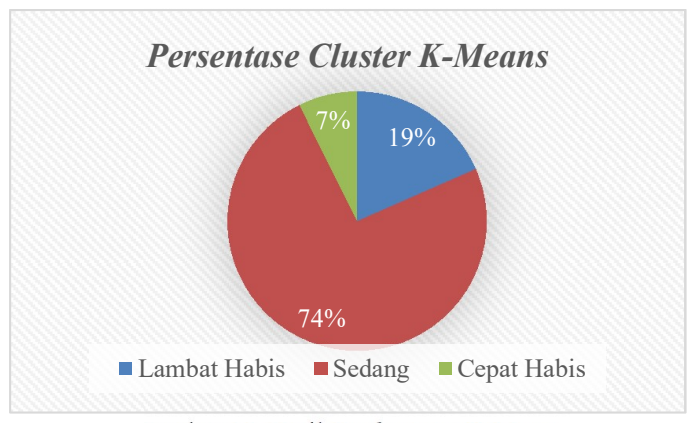

Gambar 15. Hasil Deployment $K$-Means

Dari hasil cluster K-Means tersebut diketahui bahwa anggota data obat yang berada di cluster lambat habis sebanyak $19 \%$ atau 30 obat, cluster sedang sebanyak $74 \%$ atau 121 obat dan cluster cepat habis sebanyak $7 \%$ atau 12 obat. Artinya penggunaan algoritma untuk K-Means didominasi oleh cluster sedang. Selanjutnya untuk algoritma $K$-Medoids dapat dilihat pada gambar 19.

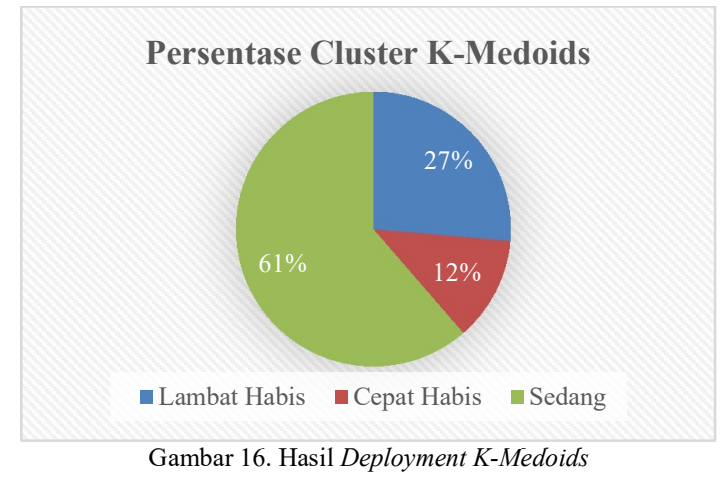

Dari hasil cluster K-Medoids tersebut diketahui bahwa anggota data obat yang berada di cluster lambat habis sebanyak $27 \%$ atau 43 obat, cluster sedang sebanyak $61 \%$ atau 100 obat dan cluster cepat habis sebanyak $12 \%$ atau 20 obat. Artinya penggunaan algoritma untuk K-Medoids didominasi oleh cluster sedang.

\section{KESIMPULAN}

Berdasarkan penelitian yang telah dilakukan dapat disimpulkan beberapa hal antara metode $K$-Means dan $K$ Medoids clustering telah berhasil diimplementasikan untuk mengelompokkan obat lambat habis, sedang, dan obat cepat habis. Penggunaan metode K-Means dan K-Medoids clustering ini menggunakan nilai $\mathrm{K}=3$. Pelabelan dilakukan berdasarkan karakteristik jumlah data stok obat dalam setiap cluster. Penelitian ini dibuat dengan menggunakan bahasa pemrograman Python. Dari perhitungan Algoritma K-Means 
dan K-Medoids menghasilkan informasi baru berupa informasi pemakaian obat yang dibagi menjadi 3, yaitu

Pemakaian obat cepat yaitu pemakaian obat yang dimana pemakaiannya membuat persediaan yang tersedia hampir habis dari analisis data mining menggunakan metode $K$ Means terdapat 12 obat dan $K$-Medoids terdapat 20 obat. Hasil tersebut dapat menjadi acuan rekomendasi puskesmas untuk lebih memperbanyak stock obat khusus nya pada pemakaian obat cepat.

Pemakaian obat sedang yaitu pemakaian obat yang dimana persediaannya masih normal dari analisis data mining menggunakan metode $K$-Means terdapat 121 obat dan $K$ Medoids terdapat 100 obat.

Pemakaian obat lambat yaitu pemakaian obat yang dimana pemakaiannya membuat tidak terlalu tinggi dan cenderung jarang digunakan dari analisis data mining menggunakan metode $K$-Means terdapat 30 obat dan $K$-Medoids terdapat 43 obat. Hasil tersebut dapat menjadi acuan rekomendasi puskesmas untuk tidak melakukan persediaan pada obat-obat tersebut dikarenakan obat yang masih tersedia banyak.

Evaluasi algoritma K-Means dan K-Medoids untuk pengelompokkan obat di puskesmas karangsambung dilakukan dengan menggunakan Silhouette Coefficient didapatkan hasil untuk K-Means sebesar 0.627 dan $K$ Medoids sebesar 0.536 sehingga dapat disimpulkan hasil cluster cukup baik dan masuk ke dalam kategori medium structure.

\section{DAFTAR PUSTAKA}

[1] J. J. Tinangon, F. Ekonomi, and J. Akuntansi, "Analisis Pengendalian Internal Atas Persediaan Obat Pada Organisasi Sektor Publik Di Puskesmas Bahu," J. EMBA J. Ris. Ekon. Manajemen, Bisnis dan Akunt., vol. 7, no. 3, pp. 3099-3108, 2019 , doi: 10.35794/emba.v7i3.24062.

[2] S. Chaira, E. Zaini, and T. Augia, "Drugs Management Evaluation at Community Health Centers in Pariaman City, Indonesia," $J$. Sains Farm. Klin., vol. 3, no. 1, pp. 35-41, 2016, [Online]. Available: http://jsfkonline.org/index.php/jsfk/article/view/97.
[3] M. Harahap, A. M. Husein, S. Aisyah, F. R. Lubis, and B. A. Wijaya, "Mining association rule based on the diseases population for recommendation of medicine need," J. Phys. Conf. Ser., vol. 1007 , no. 1, pp. $0-11,2018$, doi: 10.1088/17426596/1007/1/012017.

[4] Z. Ceylan, S. Gürsev, and S. Bulkan, "An Application of Data Mining in Individual Pension Savings and Investment System," no. January, pp. 7-11, 2018

[5] M. Mardalius, "Pemanfaatan Rapid Miner Studio 8.2 Untuk Pengelompokan Data Penjualan Aksesoris Menggunakan Algoritma K-Means," Jurteksi, vol. 4, no. 2, pp. 123-132, 2018, doi: 10.33330 /jurteksi.v4i2.36.

[6] R. D. Firdaus, T. G. Laksana, and R. D. Ramadhani, "Pengelompokan Data Persediaan Obat Menggunakan Perbandingan Metode K-Means Dengan Hierarchical Clustering Single Linkage," J. Informatics, Inf. Syst. Softw. Eng. Appl., vol. 2, no. 1 , pp. 33-48, 2019, doi: 10.20895/inista.v2i1.87.

[7] S. Sundari, I. S. Damanik, A. P. Windarto, H. S. Tambunan, J. Jalaluddin, and A. Wanto, "Analisis K-Medoids Clustering Dalam Pengelompokkan Data Imunisasi Campak Balita di Indonesia," Pros. Semin. Nas. Ris. Inf. Sci., vol. 1, no. September, p. 687, 2019, doi: $10.30645 /$ senaris.v1i0.75.

[8] P. Kumar and D. Sirohi, "Comparative analysis of FCM and HCM algorithm on Iris data set," Int. J. Comput. Appl., vol. 5, no. 2, pp. 33-37, 2010, doi: 10.5120/888-1261.

[9] A. Azevedo and M. F. Santos, "Kdd, Semma And Crisp-Dm : A Parallel Overview Ana Azevedo and M . F . Santos," IADIS Eur. Conf. Data Min., pp. 182-185, 2008, [Online]. Available: http://recipp.ipp.pt/handle/10400.22/136\%0Ahttp://recipp.ipp.pt/b itstream/10400.22/136/3/KDD-CRISP-SEMMA.pdf.

[10] M. Robani and A. Widodo, "Algoritma K-Means Clustering Untuk Pengelompokan Ayat Al Quran Pada Terjemahan Bahasa Indonesia," J. Sist. Inf. Bisnis, vol. 6, no. 2, p. 164, 2016, doi: 10.21456/vol6iss2pp164-176.

[11] C. Yuan and H. Yang, "Research on K-Value Selection Method of K-Means Clustering Algorithm," $J$, vol. 2, no. 2, pp. 226-235, 2019, doi: 10.3390/j2020016.

[12] D. Marlina, N. Lina, A. Fernando, and A. Ramadhan, "Implementasi Algoritma K-Medoids dan K-Means untuk Pengelompokkan Wilayah Sebaran Cacat pada Anak," J. CoreIT J. Has. Penelit. Ilmu Komput. dan Teknol. Inf., vol. 4, no. 2, p. 64, 2018, doi: 10.24014/coreit.v4i2.4498.

[13] P. J. Rousseeuw, "Silhouettes: A graphical aid to the interpretation and validation of cluster analysis," J. Comput. Appl. Math., vol. 20, no. C, pp. 53-65, 1987, doi: 10.1016/0377-0427(87)90125-7.

JAIC Vol. 5, No. 2, Desember 2021: 109 - 116 